\title{
COOPERAÇÃO EM CADEIAS PRODUTIVAS: UM DEBATE ENTRE A ECONOMIA DOS CUSTOS DE TransaÇão e a ECONOMIA do APRENDIZAdo
}

\author{
Rodolfo Torres dos Santos ${ }^{1}$
}

\section{INTRODUÇÃO}

O presente artigo discute a explicação da economia do aprendizado e da economia dos custos de transação para a formação de estruturas de cooperação em cadeias produtivas. Estas estruturas utilizam formas de organização e coordenação das relações econômicas mais complexas que o sistema de preços de mercado. A abordagem da teoria dos custos de transação para este fenômeno é que tais estruturas emergem da busca por mitigação de riscos associados aos investimentos em ativos específicos. Para a economia do aprendizado, a formação de associações numa cadeia produtiva é explicada pelo benefício da geração e difusão de conhecimento entre as partes. Neste estudo se constrói uma argumentação em defesa da complementaridade destes enfoques, sobretudo tendo em foco que os fenômenos do mundo real apresentam simultaneamente os requisitos destas duas interpretações. Atenção especial será dedicada às relações verticais para compreender a cooperação entre agentes de diferentes elos da cadeia produtiva.

$\mathrm{Na}$ análise econômica tradicional, o processo de decisão dos agentes econômicos possui, como traço característico, a maximização de função objetivo. Ainda nesta perspectiva, a forma suficiente, e mais eficiente, de concatenar as decisões individuais dos agentes econômicos passa por relações anônimas de mercado. No entanto, em diversas atividades de geração de valor na economia capitalista contemporânea, destacam-se o papel da cooperação entre firmas no desenvolvimento de atividades que se distanci-

1 Doutorando e pesquisador do IE/UFRJ. e-mail: rotor@bol.com.br 
am do perfil de mercado puro. Tais formas de cooperação caracterizam-se por ações complementares ao papel exercido pelo sistema de preços como forma de coordenação.

Alternativamente à concepção neoclássica, as abordagens teóricas mencionadas acima permitem um tratamento mais adequado para fenômeno de formação de relações, entre firmas em uma cadeia produtiva, em substituição ao mercado. A economia dos custos de transação fornece elementos para se discutir as relações verticais com base na presença de custos de coordenação das transações econômicas. A economia do aprendizado destaca os benefícios da interação entre os agentes de uma cadeia produtiva em termos de ampliação do conjunto de competências das firmas. Tais abordagens são independentes e possuem características particulares, dando margem para um debate recente na teoria econômica quanto à complementaridade destes enfoques. ${ }^{2}$ Diante disso, o presente estudo visa reunir alguns argumentos e dar uma modesta contribuição a este debate no âmbito das redes verticais de cooperação.

Para tanto, a segunda seção apresenta um rápido resumo das abordagens da teoria dos custos de transação e da economia do aprendizado, principalmente no que tange as relações verticais na cadeia produtiva. $\mathrm{Na}$ terceira seção busca-se, através de uma resenha ao debate entre estas duas correntes, encontrar os limites e as possibilidades de utilizar um quadro analítico integrado destas teorias. Por fim, a quarta e última seção trazem as considerações e algumas possíveis implicações de política industrial que podem ser tiradas deste debate teórico. A título de conclusão, argumenta-se que existem pontos favoráveis em se usar em conjunto as abordagens aqui consideradas para o estudo das redes de cooperação vertical em cadeias produtivas.

\title{
A INTERAÇÃO ENTRE FIRMAS EM CADEIAS PRODUTIVAS: INTEGRAÇÃO VERTICAL E NETWORKS
}

\author{
O Enfoque da Teoria dos Custos de transação
}

Os custos de transação referem-se aos dispêndios de recursos para a formulação de contratos. $\mathrm{O}$ termo contrato não se refere apenas a aspectos jurídicos, mas também a acordos tácitos e informais envolvidos em uma transação que se desenvolve no tempo, na forma de compromissos

2 0ver Foss (1999); Lundvall (1993); Winter (1991) e Teece (1986). 
intertemporais. Diante disto, abre-se a dicotomia entre custos de transação ex-ante e ex-post. O custo ex-ante surge no ato de redigir e negociar os termos da transação, incluindo garantias quanto a eventuais problemas no decorrer desta. Diante destas contingências contratuais, surge a necessidade da adaptação ao novo ambiente de transação, sendo, portanto, inviável a consolidação de contratos completos, no sentido de antecipar todas as formas de solucionar futuros litígios entre as partes da transação.

Os custos de montar estruturas de correção a tais eventualidades, além do próprio fracasso destas (má adaptação), consiste nos custos de transação ex-post. Nestes inclui-se o custo de acionamento de uma terceira parte (arbitragem) para avaliar os desentendimentos entre as partes da transação, diante do caráter incompleto dos contratos numa economia sujeita a eventos imprevistos. Quanto mais se considere a economia como sujeita a fatores dinâmicos, maior será o perfil de contratos incompletos em uma transação. Entre outros fatores, a complexidade do ambiente é uma característica da economia capitalista contemporânea, devido à dinâmica tecnológica.

Para Williamson (1985), a situação relevante para análise se dá na presença simultânea dos fatores: i) racionalidade limitada; ii) oportunismo; iii) incerteza comportamental.

O conceito de racionalidade limitada, proposto por Herbert Simon (1979), é uma hipótese alternativa à visão de racionalidade substantiva dos agentes na teoria neoclássica. Diante da complexidade do ambiente em que o agente se insere, ele é restringido a exercer sua capacidade de maximização de benefício, passando a adotar critérios de satisfação, onde se destaca o papel de racionalidade no procedimento (procedural rationality). Williamson aponta duas formas a estes limites, um físico, de receber e processar as informações, e outro de linguagem, inaptidão de articular os conhecimentos através dos mecanismos usuais de comunicação.

Oportunismo é um conceito central para a análise dos custos de transação. As vantagens contratuais decorrentes do oportunismo referem-se à aquisição de informações seletivas e na transmissão distorcida destas. O agente oportunista, na teoria dos custos de transação, é o que se compromete com algo que sabe, de antemão, não poder cumprir, como também não revela a informação a baixo custo à outra parte. Um desdobramento do oportunismo é o uso da assimetria de informação para obter rendas na execução (ou má execução) dos contratos. Além disto, o oportunismo cresce diante da presença reduzida de participantes habilitados para a transação, small numbers.

A incerteza no enfoque da teoria dos custos de transação é o terceiro elemento que determina a dificuldade e os custos em se realizar 
transações econômicas, pois em condições de certeza, mesmo que um agente não seja considerado possuidor de racionalidade substantiva e transacione com outros atores potencialmente oportunistas, não haveria problemas em se delimitar os parâmetros transacionais (que vão além do preço e quantidade), pois se poderiam antecipar eventuais litígios ex-ante.

Dados os condicionantes para que seja significativo se considerar os custos de transação, o que determina que estes ocorram em maior ou menor grau serão as características do bem ou serviço transacionado. Destaca-se a freqüência, ou seja, se as interações entre os agentes que transacionam determinado produto ocorre de forma esporádica ou de maneira sistemática, e o grau de especificidade do ativo transacionado. Este último é um conceito chave para esta teoria, merecendo ser avaliado em maior detalhe.

Williamson (1991, p. 281) afirma que a especificidade de ativos pode se apresentar de seis diferentes formas. A primeira é especificidade de ativos gerada por fatores locacionais (site specificity), ocorre quando as etapas do processo de produção demandam a proximidade geográfica para economizar em custos de transporte e estoque: mais que isto, representam situações onde a substituição da parte na transação implica o custo de transferir unidades produtivas. Uma segunda forma é a especificidade no tempo, que constitui um caso particular da primeira fonte de ativos específicos; engloba processos produtivos onde o fim de um estágio de produção e o início de outro dependem de coordenação e sincronismo. Um terceiro aspecto que determina a especificidade ocorre quando determinado processo produtivo requer aplicações de capital em ativos fixos específicos à transação entre diferentes estágios, ou seja, quando as partes desenvolvem processos ou produtos que não possuem substitutos próximos no mercado. Um desdobramento destes é o fornecimento de ativos dedicados (complementares), onde uma parte da transação emprega recursos (não necessariamente capital fixo) para atender às exigências particulares da outra parte, implicando custos elevados caso o relacionamento se desfaça. Nestes dois últimos casos, a expansão da capacidade produtiva é dimensionada e direcionada para determinadas demandas, onde a interrupção do processo produtivo repercute em ociosidade no uso do ativo e seus custos subseqüentes. Por fim, a sexta fonte de especificidade é originada no aprendizado produtivo (learning by doing) desenvolvido para atender determinada transação sem substitutos próximos no mercado, para o que Williamson atribui o termo human-asset specificity. ${ }^{3}$

3 Para a discussão das fontes de especificidade de ativos ver também Williamson (1985, p. 55) e Pondé (1994, p. 26). 
O problema com investimentos em ativos específicos é que não há como se transferir para outros usos e por não existir um mercado de revenda. Assim, quanto mais específico o ativo maior será o sunk-cost do investimento, configurando-se em um problema para o contratado (fornecedor). Já o contratante (cliente) fica condicionado a apenas um agente, perdendo as vantagens de uma transação num mercado competitivo, uma vez que a transação via mercado funcionará melhor quanto mais padronizado for o ativo em questão. ${ }^{4}$

O oportunismo dos agentes econômicos, numa relação vertical, associa-se à extração de quase-rendas da outra parte da transação através de ameaças de rompimento da relação (contrato), caso concessões de preço não sejam realizadas. Logicamente, este problema tem dimensão relevante quando não há outro agente habilitado no mercado para substituir o parceiro corrente na transação, ou seja, quanto mais específicos os ativos dedicados à transação.

O argumento da teoria dos custos de transação é que quanto maior a especificidade do bem ou serviço transacionado e quanto mais freqüente seja a interação entre os agentes da transação, maior será a demanda por estruturas que governem a relação (governance structure) de forma mais centralizada. No limite estaria a firma integrada verticalmente e em uma situação intermediária, chamada de formas híbridas, estariam as redes de firmas.

Neste contexto, o importante é que a integração promove o alinhamento de interesses permitindo ganhos através de uma melhor adaptação cooperativa dos agentes. ${ }^{5}$ Portanto, a principal explicação para a integração vertical seria a eliminação do conflito de interesse e o alinhamento de incentivos através do papel exercido pela hierarquia da firma, reduzindo o problema de incerteza comportamental. A vantagem da organização interna é o poder de adaptação no momento em que ocorre um problema sem que se faça necessário consultar uma outra parte, dado que se podem estabelecer mecanismos de avaliação de desempenho internos à firma. Na firma, o papel da hierarquia é estabelecer instâncias superiores que atuem de forma ágil sobre disputas entre diferentes atores. Assim, substituem-se as negociações entre duas entidades empresariais independentes por mecanismos de

4 Logo, quanto maior o caráter de commodity, menor o problema em termos de transação via mercado, mas a questão é que os bens e serviços de alto valor adicionados e de grande responsabilidade na dinâmica competitiva, inclusive das nações, são muito mais complexos e pouco padronizados.

5 Williamson, 1975, p. 84. 
decisão administrativa, que passam a ser responsável pela implementação de adaptações na conduta dos agentes. ${ }^{6}$ Isto também pode ser ampliado para analisar as redes, na medida que se estabeleça uma hierarquia interna ao arranjo de firmas.

A especificidade de ativos pode ser associada à complexidade tecnológica envolvida em processos inovativos, uma que criar algo "novo" implicará, em maior ou menor grau, em se dedicar ativos aos processos distintos do seu uso corrente (padrão). Assim, ao se considerar a inovação como algo que "quebra", ou substitui, padrões de produtos ou processos estabelecidos no mercado, necessariamente estarão se alterando os padrões de relacionamento vertical na cadeia produtiva, sobretudo quanto à especificidade de bens e serviços que suportam as transações. Isto pode implicar na montagem de redes de cooperação de firmas ou, no limite da especificidade do ativo em questão, à própria integração vertical.

As redes de firmas podem ser avaliadas como estruturas de coordenação, mas neste caso, a condição necessária é que o nível de custos de transação seja inferior ao associado à integração vertical. Uma vez que a freqüência das transações em um arranjo em rede é evidentemente elevada, o que determina as estruturas em rede seria um grau de especificidade de ativos inferior ao que se avaliaria como determinante para um processo de verticalização. Além disso, as redes também podem ser resultado de um esforço de firmas em gerar um salto qualitativo dos produtos de sua cadeia produtiva. Desta forma, mais do que uma forma eficiente de coordenar transações, os vínculos entre firmas podem ser avaliados como uma forma eficaz para estimular o processo inovativo, viabilizando a busca de novas oportunidades tecnológicas. ${ }^{7}$

Diante das especificidades da transação com bens e serviços complexos e pouco padronizados transacionados, a rede surge da necessidade de se estabelecer contratos para a gestão da transação que vão a além da simples coordenação da transação via "mercado puro". A questão para este enfoque teórico é que as redes de firmas, enquanto relação contratual, se caracterizam por mecanismos que mitiguem práticas oportunistas de agentes participantes do arranjo, dada a dificuldade e o alto custo envolvido de substituição do parceiro na transação vertical. Isto porque, na presença de ativos específicos, assegurar a continuidade da transação é uma questão fundamental para a decisão de investir.

\footnotetext{
6 Pondé (1993, p. 43)

7 Britto (1999, p. 105)
} 
O desafio para a relação bilateral é gerar um mecanismo flexível de ajustamento com franco comprometimento das partes. Nestes contratos os planos não devem ficar completamente acertados previamente, pois seria mais custoso tentar cumprir metas acertadas ex-ante. Por exemplo, não há como saber de antemão qual será a "quase renda" gerada na transação e, sobretudo, se esta tenderá a se distribuir de forma simétrica entre os agentes participantes do arranjo. A repartição dos benefícios gera motivo para barganhas, cujo resultado pode inviabilizar os potenciais benefícios. A questão é que os agentes possuem um alto custo de saída e buscam soluções para as barganhas envolvidas que são tanto maiores quanto menor o número de participantes. Nestes casos, a criação de um sistema de incentivos para manter a relação é uma possível alternativa. Estes incentivos vão desde ônus por descumprimento contratual até o comprometimento (commitment) de capital. ${ }^{8}$ Mesmo assim, a negociação contratual pode ser inviável, sendo imprescindível a presença da arbitragem para a transação.

Em suma, a questão central nesta abordagem teórica são os custos que uma transação com ativos específicos pode assumir em uma rede de firmas, custos estes associados a condutas que se desviem do interesse coletivo do arranjo de firmas. Desta forma, a rede se justificaria como uma estrutura de compatibilização da racionalidade individual em favor da racionalidade coletiva. ${ }^{9}$ Portanto, diante da falha do comportamento não cooperativo, característico da interação via mercado puro, em orientar as decisões de cada agentes, ganham espaço as organizações cuja finalidade é adequar a racionalidade individual à racionalidade coletiva.

\section{A Abordagem da Economia do Aprendizado}

A teoria neoschumpeteriana tem como tema central entender a dinâmica da economia capitalista. Neste intuito, destaca-se a importância das inovações, que num sentido amplo não se restringem às novas tecnologias, mas também englobam esforço para modificar os canais de distribuição de produtos e a própria diversificação do escopo de atuação da

8 Onde a joint-venture seria um caso particular de esquema de incentivos que envolvem comprometimento de capital.

9 Para que isto ocorra torna-se freqüente a contratação de uma terceira parte para cumprir o papel de arbitragem da transação. 
firma. Contudo, esta linha de pensamento econômico possui diferentes abordagens. ${ }^{10}$

Uma das correntes teóricas de perfil neoschumpeteriano destaca a importância do conhecimento e o aprendizado dos agentes econômicos como fator determinante do seu desempenho econômico, ou seja, eles são fundamentais para explicar a sua competitividade. Esta é freqüentemente chamada de economia do aprendizado.

Cabe apresentar algumas hipóteses centrais desta abordagem teórica. A primeira destas é enfatizar que os agentes possuem racionalidade limitada. ${ }^{11}$ Simon (1979) argumenta que o agente tomaria suas decisões limitadas pelas condições de previsão dadas pelo ambiente; ele teria uma racionalidade limitada e não substantiva. Vale frisar que a limitação é dada pela relação entre o agente e o ambiente e não por padrões de comportamento irracionais. A racionalidade se dá no procedimento (procedural rationality), com destaque para as limitações cognitivas, ou seja, como interpretar as informações obtidas no ambiente. Torna-se mais importante o modo como os agentes se comportam no processo decisório, em detrimento do próprio resultado da escolha racional. Assim, ao invés de buscar a maximização de uma função objetivo que possui lacunas, o agente opta por soluções subótimas, as quais Simon atribui o termo de satisfacing. Comportamentos defensivos podem ser rotinas de conduta (procedural rationality) que reduzem os prejuízos dos erros de previsão que são recorrentes em um ambiente não-ergódigo, onde a informação que este fornece está repleta de erros, e os agentes não conseguem dissociar um do outro, pois os parâmetros são instáveis. Tal instabilidade torna inviável a dedução desta incerteza por uma distribuição de probabilidades, ao contrário do risco (incerteza neoclássica).

Uma segunda hipótese consiste em se considerar a informação sendo diferente do conhecimento, no sentido de que um agente pode possuir muita informação, mas ter pouco conhecimento para fazer uso eficiente disto. Pode-se dizer que esta hipótese deriva da racionalidade limitada e da incerteza forte presente em ambientes complexos. A abordagem da economia neoclássica costuma simplificar a questão reduzindo conhecimento à mera obtenção de informação.

10 A pluralidade de autores com enfoques relativamente distintos é maior do que encontrado na economia dos custos de transação.

11 Embora já tenha sido abordada a questão da racionalidade limitada no tópico anterior, uma maior abordagem se adequa melhor neste momento do trabalho. 
Rotinas, elemento central na abordagem neo-schumpeteriana, possuem um caráter específico a cada firma e expressam o conhecimento e a experiência acumulados em seu setor. Desta forma, as rotinas explicariam maior ou menor adaptabilidade à mudança. A própria firma seria explicada pelo seu conjunto de rotinas, que englobam tecnologia, produção e organização.

Outro traço marcante desta abordagem é a ampliação do conjunto de hipóteses sobre o conceito de conhecimento. A principal contribuição é destacar que o conhecimento possui um caráter tácito, ou seja, não é facilmente transferível ou comercializável em mercado. O conhecimento tácito distingue-se do explícito na medida que naquele não se pode dissociar o conhecimento de sua fonte (carregador). O importante na era do conhecimento não é adquirir informação, mas sim, saber selecioná-la e utilizá-la. As competências estão inseridas nas rotinas das organizações; conseqüentemente, pode-se considerar que esta forma de conhecimento não se seja isolável ao indivíduo, mas de fato se apresente de forma coletiva. Portanto, a aquisição de conhecimento é fundamentalmente um processo coletivo. Assim, no caso de firmas, o conhecimento associado às capacitações só é adquirido pelo contato direto (ou fusão) com outro agente. ${ }^{12}$

A diversificação de uma firma específica para indústrias com padrões de difusão distintos dos conhecidos em suas atividades no mercado de origem pode ser dificultada pela ruptura com o nível de capacitação previamente acumulado. Ou seja, uma firma que deseja diversificar verticalmente incorrerá em problemas devido às distintas capacitações necessárias para se atuar em uma nova indústria, seja esta no seguimento downstream ou upstream da cadeia produtiva na qual está inserida.

Além disso, o conhecimento depende das competências dos agentes econômicos e, sobretudo, no aprendizado, forma pela qual as competências se desenvolvem e se adequam à dinâmica do ambiente. Portanto, o conceito de aprendizado é crucial para o enfoque evolucionário. Johnson e Lundvall (2000) abordam que toda economia deve ser compreendida pelo processo de aprendizado.

A learning economy is an economy where the ability to learn is crucial for the economic success of individuals, firms, regions and national economies. "Learning" refers to building new competencies and establishing news skills and not just "getting access to information". Johnson e Lundvall (2000, p. 4)

12 Johnson e Lundvall (2000), p. 19 
O aprendizado pode ter origem: i) na experiência acumulada em exercer atividades produtivas (learning by doing); ii) na experiência acumulada no o uso de determinado bem ou serviço (learning by using); iii) na experiência acumulada na interação com os demais agentes, sejam estes clientes, fornecedores ou demais firmas da mesma indústria (learning by interacting).

Dado o objetivo de se estudar as relações verticais na cadeia produtiva (relação entre fornecedor e cliente), destaca-se o papel do aprendizado interativo no desenvolvimento deste trabalho. O interactive learning refere-se aos mecanismos de transmissão de conhecimentos e informações entre os agentes inseridos em cadeias inter-industriais. Segundo Britto (1999), diante da natureza do aprendizado não viabilizar a codificação de maneira clara e objetiva, a viabilização do processo inovativo requer interações diretas e sistemáticas, somente assim, as capacitações podem progredir mutuamente.

O mais relevante para o presente trabalho é a relação entre os diferentes graus de verticalização e a forma com que este aprendizado ocorre, como também o ritmo que evoluem as capacitações dos agentes. $\mathrm{O}$ argumento central é que um contexto institucional, como redes cooperativas de firmas e a própria integração vertical, diferentemente da impessoalidade do mercado, propicia as condições necessárias para o aprendizado.

Um dos fatores para o desenvolvimento do aprendizado interativo é a criação de formas de comunicação específicas e, sobretudo, comuns aos agentes participantes do arranjo produtivo (redes ou firma integrada). Além disso, determinado desenvolvimento tecnológico de um agente depende do potencial inovativo de todos os pontos da cadeia na qual a firma está inserida. Mais precisamente, a inovação de determinado bem final depende da capacidade dos seus fornecedores de acompanharem tais esforços para inovar. Desta forma, é factível pensar que, em determinadas situações, a firma se encontre em melhor condição para realizar ela própria o desenvolvimento de seus novos insumos, compatíveis com a sua inovação almejada no mercado de bem final. Tal fato também pode ser pensando no sentido inverso da cadeia, ou seja, determinado produtor de bens intermediários pode considerar uma melhor estratégia diversificar-se rumo ao downstream, dadas as limitações de determinados usuários para desenvolverem bens finais a partir de determinado insumo novo.

A discussão a respeito do papel do aprendizado interativo depende fortemente do contexto industrial sob investigação, principalmente quanto ao próprio dinamismo tecnológico setorial, como também da própria com- 
plexidade tecnológica e o valor unitário do bem produzido. ${ }^{13} \mathrm{~A}$ este respeito Pondé (1993) argumenta que:

Quando a tecnologia apresenta-se como a síntese ou a convergência de um amplo espectro de experiências, conjuntos de informações com maior ou menor grau de formalização, qualificações, habilidades, capacitações, etc., o aprendizado ocorre a partir de um processo coletivo e interativo. (Pondé 1993, p. 103)

Diante disto, são necessários mecanismos que sustentem o fluxo de transmissão do conhecimento (tácito e formal) para que os agentes se beneficiem do aprendizado interativo. Assim, quanto mais complexo for o aprendizado, maior o número de interações requeridas. Logo, pode-se pensar que no limite o esforço inovativo de certas firmas requeiram a integração vertical. Porém, neste mesmo contexto, existe a alternativa de que o aprendizado interativo ocorra no âmbito das redes de firmas.

Nas redes de firmas destaca-se a formação de ativos complementares para explorar adequadamente as suas competências e reforçar a interação com agentes externos. ${ }^{14} \mathrm{~A}$ importância de certa firma ter acesso aos ativos complementares de outras amplia o interesse em manter o relacionamento com caráter formal, como alianças e vários formatos contratuais. Enquanto que para firma verticalmente integrada, Armour and Teece $(1980)^{15}$ argumentam que cresce o retorno gerado pelo esforço de $\mathrm{P} \& \mathrm{D}$ por facilitar a comunicação entre os estágios de produção.

$O$ fato é que o aprendizado através da interação ${ }^{16}$ pode ter origem tanto no relacionamento interno à firma como também no externo, sendo que o primeiro trata-se da interação entre os agentes (ou departamentos) de uma firma e o segundo aos relacionamentos com fornecedores/clientes da cadeia produtiva. A definição do grau de verticalização pode ser associada à complexidade do aprendizado, uma vez que dependa de maior intensidade de interações para viabilizá-lo, considerada a dificuldade de compatibilizar os padrões de cognição e a transmissão de conhecimento tácito.

Dentro da abordagem da economia do aprendizado pode-se afirmar que o limite da firma, ou pondo de outra forma, o grau de verticalização, depende da limitação de suas competências. Neste sentindo, por mais que

13 Lundvall (1988) citado em Pondé (1993, p. 91).

14 Teece $(1986 ; 1988)$ apud Britto $(1999$, p. 115)

15 apud Perry, 1989, p. 218

16 Inclusive em sua vertente tecnológica. 
uma firma seja compreendida como um vasto e complexo leque de competências, ela possui limites em exercer atividades que não estejam relacionados com sua rotina de atividades. A maneira que as firmas podem superar esta restrição é o aprendizado interativo com outras firmas com distinto conjunto de competências. ${ }^{17}$ No limite do desenvolvimento de um novo produto ou processo, pode ser necessária a integração das competências em uma mesma unidade.

Quando as firmas se expandem através de integração vertical, não se trata de acumular os conhecimentos prévios (mais do mesmo). Neste caso, o grau de verticalização depende do nível de conhecimento relevante da firma, ou seja, só se justificam as coalizões verticais entre firmas de nexos de conhecimento complementar. Diante disto, a visão evolucionária sugere que este nível de conhecimento é um fator importante na decisão de se, como e onde realizar a integração vertical. ${ }^{18}$

Em suma, a característica marcante da economia do aprendizado é a conceber que os benefícios que o aprendizado interativo proporciona ao desenvolvimento das capacitações dos agentes envolvidos no arranjo cooperativo de firmas. Tal fato pode se manifestar como uma formação de redes de cooperação vertical entre as firmas, ou pela própria integração diante da maior necessidade de interação frente à complexidade do objetivo da relação entre os agentes (joint ventures).

\section{LIMITES E POSSIBILIDADES DE UM QUADRO ANALÍTICO INTEGRADO}

A Economia do Aprendizado versus A Economia dos Custos de Transação: uma primeira aproximação

A questão em tela passa por avaliar em que medida estas teorias podem formar uma estrutura alternativa à teoria ortodoxa para o estudo de cadeias produtivas. Neste sentido, Winter (1993) aborda que os manuais de economia falham em não prover bases para a compreensão dos incentivos e processos na firma que proporcionam mudanças técnicas e organizacionais. A discussão traçada por Winter (1993) serve de apoio para uma primeira

17 Diante do caráter específico e tácito do conhecimento o aprendizado interativo também seria uma justificativa para a cooperação horizontal.

18 Winter, 1993, p. 191. 
aproximação à discussão dos limites e possibilidades de um quadro analítico que utilize tanto a teoria dos custos de transação quanto a economia do aprendizado, para compreender as relações verticais na cadeia produtiva.

Like transaction cost economics, evolutionary economics tends to direct attention to observed economic behavior rather than hypothetical sets of alternatives (...) it regards understanding of the ongoing, interrelated processes of change in technology and organization as the central intellectual problem to be confronted by a theory of the firm. (Winter, 1993, p. 187)

Contrapondo-se ao enfoque ortodoxo, estas teorias não se apoiam na hipótese comportamental racionalidade substantiva. Como pôde ser observada acima, tanto a economia do aprendizado quanto a economia dos custos de transação emprega o conceito de racionalidade limitada cunhado por Herbert Simon.

O foco principal da teoria evolucionária está ligado ao entendimento dos fenômenos que ocorrem no âmbito da esfera produtiva, sobretudo aqueles que possibilitem à firma inovar. Além disso, inovações podem levar a novas rotinas que reduzem a complexidade e incerteza no procedimento do agente inovador (Dosi e Egidi, 1991). Por outro lado, a teoria dos custos de transação se coloca sobre os problemas do alinhamento de incentivos e o oportunismo dos agentes, que logicamente tem origem contratual transacional. Pelo fato de a visão ortodoxa atentar tanto para aspectos transacionais como para a esfera da produção, uma abordagem heterodoxa mais completa deveria atender também a ambos os aspectos. Daí, uma motivação para se buscar as complementariedades da teoria dos custos de transação e da teoria evolucionária. Não obstante, várias questões relevantes para compreender o desempenho das firmas decorrem simultaneamente de variáveis ligadas tanto a produção quanto a dimensão transacional. ${ }^{19}$ Por exemplo, o próprio dimensionamento das rotinas das firmas, inclusive as rotinas de inovação, ${ }^{20}$ são condicionadas por fundamentos organizacionais que as regem, como rotinas organizacionais.

A mudança na estrutura de governança propicia vantagens competitivas para a firma que realiza este movimento à frente de as rivais; por outro, nada pode ser afirmado quanto à capacidade das rivais acompanha-

19 “A tecnologia e organização devem ser tratadas como variáveis de decisão a serem determinadas simultaneamente, onde uma condiciona a outra" (Pondé, 1993, p. 43).

20 Dosi \& Egidi (1991). 
rem esta estratégia. A discussão sobre a capacidade de imitar as firmas inovadoras é fator determinante da competitividade na abordagem neoschumpeteriana.

Winter atribui esta limitação da teoria dos custos de transação ao fato de se preocupar com a mudança organizacional, sem considerar os problemas na alteração no ambiente e sua interdependência com a forma institucional escolhida. Neste sentido, as relações na rede podem ser alteradas pelos padrões freqüentemente adotados. A forma de atuação da firma depende fortemente de ajustes incrementais num ambiente complexo e interdependente. ${ }^{21}$ Desta forma, tratar de maneira estanque a organização em redes ou firmas, como uma dicotomia, é uma limitação, devido à concepção estática do pensamento da teoria dos custos de transação. ${ }^{22}$

\section{As relações entre a economia do aprendizado e a abordagem contratual}

Nesta seção algumas questões levantadas no item anterior serão novamente discutidas, porém buscando debater a viabilidade, ou não, de integrar as abordagens da economia do aprendizado e a abordagem dos custos de transação. Neste intuito, a referência base são os trabalhos de Nicolai Foss, pois aborda explicitamente o tema de se constituir um arcabouço de análise que integre as duas correntes teóricas versus o "isolamento" destas. ${ }^{23}$ Além disso, o trabalho de Foss (1996) permite colocar o debate avaliando-se as relações existentes entre contratos incompletos e a economia do aprendizado.

Foss (1999) defende o argumento que a economia do aprendizado e a teoria dos custos de transação podem constituir um algoritmo de análise integrado. Isto se dá, sobretudo, quando existem fortes efeitos de interação (complementariedades ou trade-off) entre a estrutura de governança e o conhecimento.

$21 \quad$ Winter, 1993, p.191

22 Ao assumir a hipótese de racionalidade limitada, pode-se derivar o fato de heterogeneidade das firmas, embora não seja um tema abordado por Williamson $(1975 ; 1985)$

23 Foss (1999) utiliza o termo isolacionismo para designar a tese de que ambas corrente teóricas devem ser mantidas em separado, enquanto o termo integracionismo é utilizado para a tese que ambas deveriam se complementar na formação de um quadro teórico mais abrangente. 
Foss (1999, p. 727) afirma que para uma teoria realizar uma análise completa da firma é preciso abordar dois conjuntos de questões. O primeiro refere-se aos limites da firma, abrangendo também fatores ligados à organização interna e de sua própria existência. Um segundo bloco estaria relacionado com os fatores determinantes da competitividade, ou vantagem competitiva, das firmas. A economia do aprendizado estaria, tradicionalmente, ligada a este último, enquanto a teoria dos custos de transação ${ }^{24}$ estaria intimamente ligada ao anterior. Porém, recentemente, estas abordagens teóricas vêm cruzando os limites de seu objeto inicial de análise.

Um aspecto central que se pretende apresentar aqui é que a determinação de um adequado aparato contratual é fundamental para o desenvolvimento das capacitações e, por sua vez, implicando no desenvolvimento tecnológico das firmas. Na falta de um arcabouço contratual satisfatório para proteger os ativos, as partes envolvidas podem incorrer em soluções tecnológicas mais simples (menos específicas), mas com menor eficiência produtiva e dinâmica. Com efeito, dados os riscos de oportunismo, o aprendizado tecnológico pode ficar aquém das possibilidades. $O$ fato é que o conhecimento relevante de ser analisado envolve um conjunto ou arranjo de agentes (aprendizado interativo) que requer alguma forma de coordenação, ao contrário da concepção do conhecimento enquanto pertencente a um agente individual. Isto visa identificar como a teoria dos custos de transação pode contribuir para a economia do aprendizado.

Além disso, certos fatores chaves para a determinação de estruturas contratuais (ou de governança) decorrem de aspectos intimamente observados pela economia do aprendizado (ou do conhecimento). Por exemplo, a especificidade de ativos, fundamental na construção da teoria dos custos de transação, pode decorrer de aspectos ligados ao desenvolvimento de novos produtos ou processos que são eminentemente específicos. Mais precisamente, o argumento é que o conhecimento delimita os ativos e as atividades que podem ser definidas, ou seja, restringe o espaço factível para os contratos. Em outras palavras, as capacitações alteram os custos de produção, este diferencial de custos influencia a decisão de make-or-buy. Portanto, há como se estabelecer um elo entre as capacitações e a determinação do nível de integração vertical necessário para coordenar (governar) determinada transação.

Complementando a argumentação acima, Foss (1996) avalia a formação de contratos incompletos, como uma forma de economia do aprendi-

24 O autor costuma a se referir a esta abordagem teórica como economics of organization. 
zado. Como visto na seção II, a necessidade de se estabelecer contratos incompletos decorre da racionalidade limitada dos agentes em lidar com fenômenos tomados por fatores geradores de incerteza. A natureza da incerteza está associada ao comportamento oportunista dos agentes diante de eventos contigentes. Tais eventos estão ligados à dinâmica do ambiente e à alteração das características do objeto da transação no tempo. Desta forma, não parece incorreto afirmar que a necessidade de se estabelecer contratos incompletos segue da incerteza quanto ao padrão tecnológico do ativo transacionado e dos fatores que suportam a transação deste.

The internal structure of firms may not just reflect incentive alignment but may also reflect the costs of transmitting knowledge. (RADNER, 1996) ${ }^{25}$

Contudo, Foss (1996) busca enfatizar os benefícios que podem ser derivados do caráter aberto dos contratos incompletos. Para o autor, estes contratos são uma alternativa de adaptação para as organizações, constituindo uma forma de coordenação do processo de aprendizado entre os indivíduos inseridos no contexto da firma ou num arranjo tipo rede.

Since individual learning processes, and perhaps even more so, organizational learning processes, imply the emergence of unforeseen contingencies, incompleteness of contracts and (organizational) learning would seem to be closely intertwined concepts. (Foss, 1996, p. 11)

Tal relevância deve-se à impossibilidade de os agentes anteciparem os benefícios do aprendizado, pois não sabem a forma explícita pela qual irá ocorrer. Como Foss (1996, p. 10) afirma, o aprendizado futuro não pode ser antecipado plenamente, pois do contrário apenas se definiria aprendizado presente.

Isto desemboca na questão da limitação cognitiva dos agentes em compreender os processos, principalmente novos, diante da racionalidade limitada em ambientes complexos e dinâmicos. Note que o mercado standard representa uma estrutura de coordenação limitada para desenvolver a base cognitiva de referência para os agentes em ambientes incertos. Neste aspecto as estruturas hierárquicas (firmas ou redes com liderança destacada),

25 Citado em Foss (1999, p. 736). 
possuem maior capacidade de respostas às circunstâncias imprevistas, ou seja, possui maior flexibilidade. ${ }^{26}$ Mas, estes ganhos de flexibilidade também decorrem da economia que a hierarquia representa em termos de custos de barganha entre os agentes caso a transação ocorresse em mercado. Mais do que isto, a flexibilidade é ampliada porque a firma desenvolve o conhecimento coletivo (organizational knowledge) que reduz custos com várias formas de informação e coordenação ao facilitar a interpretação, comunicação, e manejo com contingências imprevistas.

Tal aspecto pode ser relacionado ao acúmulo de competências em lidar com eventos imprevistos através do tempo. Assim, ele faz parte da explicação da dinâmica de aquisição de conhecimento da firma, isto é, do seu aprendizado.

In other words, the firm is needed when there is strong interdependence between the various learning process that result in new options. The coordination of such learning processes requires a framework of incomplete contracts, because there is a need for being able to react to and adapt to unforeseen contingencies that arise during the process of learning. (FOSS, 1996, p.16)

Semelhante à abordagem de Williamson (1985), Foss (1996, p.170) expõe que a hierarquia só se justifica quando o objeto transacionado (ou produzido) na cadeia produtiva é complexo e requer ativos específicos. Por outro lado, as commodities podem ser bem coordenadas pelo mercado, pois os problemas de design são resolvidos por instâncias provedores do padrão de comercialização. Ou como aborda Lundvall (1993):

I expect the weakest user-producer relations when product characteristics are both technically stable and standardized in terms of quality. (LUNDVALL, 1993, p. 61)

26 "The flexibility effect refers to the superior flexibility that hierarchy may obtain relative to market contracting in influencing input-owners' actions in response to partly unexpected new developments and new learning”. (FOSS, 1996, p. 12) 


\section{Integrando a abordagem da economia do aprendizado e da economia dos custos de transação}

Esta seção busca reunir alguns argumentos que foram expostos ao longo deste trabalho para tentar justificar as complementariedades e/ou convergências das abordagens teóricas aqui em debate. Mais do que isto, busca-se aqui dar algumas interpretações para o tema em questão.

Primeiramente, foi afirmado que as teorias da economia dos custos de transação e a economia do aprendizado serviriam como enfoques complementares, na medida que uma atenta para questão da transação enquanto outra, para a ótica da produção. Além disso, foi apontado que estas teorias comungam do conceito de racionalidade limitada crucial para destingui-las da abordagem neoclássica.

A concepção de que os agentes econômicos têm limitações no exercício de sua racionalidade diante da complexidade do ambiente incerto no qual se inserem. Tal fato, perante relações que se desenrolam no tempo e que necessitem ou envolvam ativos específicos, ${ }^{27}$ demanda a formação de organismos (instituições) que coordenem a relação entre os agentes, cumprindo funções que não cabem ao mercado realizar.

Daí existiriam várias alternativas, entre elas a rede e a integração vertical, mas todas são caracterizadas pelo uso de contratos incompletos na estrutura de coordenação. A questão é que para uma teoria isto se justifica pela maior liberdade de ação para reduzir os custos de transação ex-post, enquanto que para outra abordagem, serve para prover os benefícios do aprendizado diante de eventos inesperados. O benefício ocorre em responder mais rápido a determinados eventos, significando um crescimento das competências da firma.

Diante deste contexto, a economia do aprendizado, justifica a formação de redes (networks) e mesmo a integração vertical diante dos benefícios obtidos pelos agentes através do desenvolvimento das competências, como fruto das relações verticais mais estritas do que as factíveis pelo mercado. Por outro lado, na economia dos custos de transação, a concepção da firma, ou das redes destas, deve-se aos custos em se utilizar o mercado como instância de coordenação. Neste aspecto, embora por definições particulares a cada enfoque, a conclusão comum é que existem circunstâncias em que utilizar o mercado não representa a melhor alternativa.

27 Também foi argumentado que a especificidade de ativos pode ter como exemplo bens e serviços envolvidos no processo inovativo. 
Por um lado, a economia do aprendizado não põe ênfase na questão dos comportamentos oportunistas dos agentes, como é feito pela teoria dos custos de transação. Por outro lado, esta última não é capaz de explicar os diferenciais de competitividade que podem ser obtidos com a interação entre os agentes para ampliar o conjunto de competências. Esta seria uma justificativa para o uso simultâneo destes enfoques.

Um contraponto é feito por Lundvall (1993, p. 56) ao afirmar que o aprendizado interativo gera benefícios mútuos para as partes envolvidas que pode compensar maiores custos de produção e transação custos. No entanto, diante do fato não antecipado, que implique custos ou benefícios coletivos, coloca-se a questão de como se dá à repartição destes. Por exemplo, no caso de uma rede de firmas, como se define a repartição da renda gerada pela cooperação? Os frutos do aprendizado pode ser assimetricamente distribuídos, e neste caso, surgiriam os problemas de barganha considerados pela teoria dos custos de transação. ${ }^{28}$ Desta forma, não parece incorreto pensar que possa haver uma situação limite em que tais disputas por fluxo de lucro podem inviabilizar a cooperação em uma cadeia produtiva. ${ }^{29}$

As firmas dependem de atributos que transpõem a esfera das rotinas, mas também considerando os fatores que podem implicar um desvio deliberado das rotinas, por parte de alguns agentes do arranjo em benefício próprio, mas que não sejam compatíveis com a racionalidade coletiva. Neste intuito, cabe observar que: "A organização de uma empresa [ou arranjo produtivo em rede] deve ser considerada não só como um conjunto de papéis ou rotinas a serem seguidas, mas também como um conjunto de salvaguardas contra rupturas frente a estas e a conseqüente emergência de comportamentos desviantes." (PONDÉ, 1993, p.44)

Portanto, parece necessário não só considerar quais os benefícios que incitam os agentes a aderir uma determinada rede, mas também nos custo que podem surgir no decorrer do tempo quanto à repartição de renda entre as partes envolvidas. Logo, torna-se necessário avaliar qual a estrutura de governança (ou de coordenação) que poderá mitigar tais desalinhamentos de interesse. ${ }^{30}$ Em suma, parece que utilizar em conjunto

28 Tais conflitos, como se sabe são agravados pelo oportunismo dos agentes ao saber que seus parceiros não encontraram alternativas em mercado, diante da especificidade dos ativos que estão envolvidos.

29 Note que isto é um problema que surge no tempo, após sucessivas interações entre os agentes, logo uma questão intertemporal.

30 Como abordado na seção II.1 uma alternativa pode ser inclusive a adoção de um árbitro para transação. É neste intuito que na próxima seção aponta-se um canal para as implicações de política industrial. 
ambos os enfoques teóricos constitui um quadro analítico mais completo para a análise de complexos verticais de produção, pois se pode compreender não só os benefícios da formação da rede ou da integração, mas também quais os custos de transação envolvidos no monitoramento e no alinhamento de incentivos deste arranjo. E como se buscou mostrar acima, existe um leque de questões que só podem ser avaliadas pelo uso conjunto destes enfoques.

\section{CONSIDERAÇÕES FINAIS: ALGUMAS IMPLICAÇÕES PARA POLÍTICA INDUSTRIAL}

Durante o presente artigo, discutiram-se as interseções e complementariedades analíticas da teoria dos custos de transação e a economia do aprendizado. Neste intuito, se observou que o importante ao abordar o limite da firma (ou seu grau de verticalização) depende das capacitações para uma visão, e por outra, das definições da estrutura de transação que coordene a relação. Mais precisamente, o que se pode frisar é que a primeira abordagem devota atenção aos benefícios gerados nas relações verticais, enquanto a abordagem contratual centra-se nos custos de se coordenar as relações verticais perante determinadas características do objeto de transação.

Diante do que foi anteriormente discutido, parece importante considerar que, perante determinadas características como especificidade de ativos, muito recorrente em processos de inovação, redes de firmas ou a própria integração (vertical) são alternativas para um relacionamento vertical que seria inviável em termos de custo de transação ao ser realizado via mercado standard, dado que o único instrumento de coordenação seria a sinalização dada pelo sistema de preços. ${ }^{31}$ Mais do que isso, o estímulo às redes de firmas se justificaria pelo seu potencial de desenvolvimento das capacitações e sua repercussão na maior competitividade das firmas. ${ }^{32}$

Por outro lado, chegou-se à conclusão de que o funcionamento destes arranjos, sobretudo as redes, é vulnerável a problemas de custos de transação para compartilhar a quase-renda transacional - ou os benefícios do aprendizado interativo. Diante disto, requer-se que a estrutura de governance busque reduzir tais custos de transação. A partir daí duas alternativas são possíveis:

31 No desenvolvimento de novos produtos e processos a informação do sistema de preços é muito insuficiente para induzir o movimento dos agentes.

32 Além do caráter de spillover desta que não debatido foi neste trabalho. 
i) estabelecer uma hierarquia interna ao arranjo - que poderá consistir na integração vertical ou eleger uma firma "líder" do arranjo, mantendose as autonomias patrimoniais. ${ }^{33}$

ii) estabelecer uma arbitragem externa à transação, responsável pela solução dos eventuais litígios e determinador da tarefa a ser cumprida por cada membro da rede. Ou seja, uma instância que busque compatibilizar a racionalidade individual com a racionalidade coletiva.

Diante deste quadro, ou seja, assumindo a importância destas formas institucionais de relação vertical para o desenvolvimento das vantagens competitivas das firmas, como também o seu maior potencial de geração de novos produtos e processos, qual papel a política industrial poderia assumir?

Esta resposta pode ser dividida em dois blocos, o primeiro associado ao estímulo para que as firmas cooperem entre si e o segundo relacionado aos mecanismos necessários para a estabilidade do arranjo produtivo. Embora valha notar que exista muita interdependência entre estes dois conjuntos de fatores.

Quanto ao estímulo às redes, faz necessário aproximar os agentes para que estes descubram o benefício da interação. Arranjos institucionais, como distritos industriais, poderiam servir como alternativa para aproximar os agentes - como por exemplo, apoiar o fluxo de informações entre os agentes; incentivos para que os agentes partilhem informações e desenvolvam implementações produtivas em conjunto.

Quanto à estabilidade para o desenvolvimento do arranjo produtivo, abrem-se duas possibilidades. Uma é identificar e incitar uma liderança interna ao arranjo, para que este agente sirva como um árbitro interno nos conflitos de interesse. Para tanto, uma liderança interna deve ser um agente amplamente comprometido com arranjo. Pondo em outras palavras, a firma que possua maiores sunk-cost com o arranjo e que possua menos alternativas para empregar seus ativos, caso a rede se desmanche, deve assumir este papel. No limite, pode ser necessária certa cobertura para o risco de realizar investimentos que não podem ser revertidos para outras aplicações.

A segunda forma para que a racionalidade individual dos agentes do arranjo se compatibilize com a racionalidade coletiva depende da formação de instituições de caráter público para funcionar como um árbitro externo e coordenar (regular) as relações entre os agentes do arranjo, sobretudo nos momentos de conflitos de interesse.

33 Tal solução levanta a discussão sobre a representatividade da liderança que não será desenvolvida aqui. 
Neste contexto, se insere a crítica de Lundvall (1993) sobre as limitações da teoria dos custos de transação para explicar as relações de cooperação vertical. $\mathrm{O}$ autor se baseia no fato que a cooperação criaria um nexo social em que se expurgaria o comportamento oportunista. Caso se assuma a validade desta hipótese, as políticas para a estabilidade das redes existentes tornam-se desprezível. Porém, embora o contexto social possa ser considerado um atributo importante no desenvolvimento das firmas, seu caráter é essencialmente específico, ou seja, haverá contextos em que o problema de mitigar o oportunismo será facilmente resolvido, em outros não, constituindo-se ainda assim em programa de política. ${ }^{33}$ Desta forma, pode-se abrir um campo de pesquisa para buscar estimar que situações tecnológicas e industriais corroboram para a eliminação do comportamento oportunista dos agentes na repartição da "quase-renda" relacional.

Por fim, cabe considerar que as conclusões deste trabalho são de caráter aberto, na medida que a própria bibliografia sobre o tema está em construção e a existente foi apenas parcialmente contemplada no presente estudo. Algumas questões, que foram abordadas, merecem maior esforço analítico e constituem tema para uma pesquisa particular. Contudo, espera-se contribuir, ainda que de forma incipiente, para o debate entre estas escolas; mais do que isto, apontar para possíveis questões de policy que podem ser objeto de estudo e ampliação da discussão em futuros trabalhos, principalmente no âmbito de arranjos verticais de produção.

\section{RESUMO}

O presente artigo discute a explicação da economia do aprendizado e da economia dos custos de transação para a formação de estruturas de cooperação em cadeias produtivas. Estas estruturas têm como características formas de organização e coordenação das relações econômicas mais complexas que o sistema de preços de mercado. A abordagem da teoria dos custos de transação para este fenômeno é que tais estruturas emergem na busca por mitigação de riscos associados aos investimentos em ativos específicos. Para a economia do

33 Pode ser dado exemplo sobre a diversidade dos possíveis contextos sociais para a mitigação do oportunismo contratual ao se considerar em diferentes países. Pode-se citar o Japão, como um caso típico, para o chamado social learning, porém em outras nações, a volatilidade institucional promove ambientes incipientes para o desenvolvimento de contextos sociais favoráveis para uma cooperação sem riscos. 
aprendizado, a formação de associações numa cadeia produtiva é explicada pelo benefício da geração e difusão de conhecimento entre as partes. Neste estudo se constrói uma argumentação em favor da complementaridade destes enfoques, sobretudo tendo em foco que os fenômenos do mundo real apresentam simultaneamente os requisitos destas duas interpretações.

Palavras-chave: cadeias produtivas, custos de transação, economia do aprendizado.

\begin{abstract}
The present paper discusses the explanation learning economy and transaction cost economy to the presence of cooperative structures in productive chains. More complex organizational and coordinating frameworks than the market price system characterize these structures. The transaction cost economy shows that these structures became from the search for the mitigation of risks related to specific asset investments. In the learning economy approach, the associative formation in a productive chain is explained by the benefits of knowledge creation and diffusion between relationship members. This paper builds an analysis in defense of the simultaneous use of these approaches in order to improve the ability of real world phenomena interpretation.

Key-words: produtive chains, transaction costs, learning economy.
\end{abstract}

\title{
REFERÊNCIAS
}

BRITTO, J. N. P. Características estruturais e modus-operandi das redes de firmas em condições de diversidade tecnológica. Rio de Janeiro, 1999. Tese (Doutorado) - Instituto de Economia, Universidade Federal do Rio de Janeiro.

. A dinâmica de diversificação produtiva da firma: em busca de um quadro analítico integrado. Rio de Janeiro, 1991. Dissertação (Mestrado) - Instituto de Economia, Universidade Federal do Rio de Janeiro.

COASE, R. The nature of firm. Economica, v. 4, p. 386-405, nov. 1937.

FAGUNDES, J.; PONDÉ, J. L.; POSSAS, M. Custos de transação e política de defesa da concorrência. Revista de Economia Contemporânea, Instituto de Economia, Universidade Federal do Rio de Janeiro, n. 2, jul./dez. 1997.

FARINA, E. Política industrial e política antitruste: uma proposta de conciliação. Revista do Ibrac, v. 3, n. 8, 1996. 
FOSS, N. J. Research in the Strategic Theory of the Firm: Isolationism and Integrationism. Journal of Management Studies, Blackwell Publishers. v. 36, n. 6, nov. 1999.

FOSS, N. J. Firms, incomplete contracts and organizational learning. DRUID Working Paper n. 96-2, Apr. 1996. Danish Research Unit for Industrial Dynamics.

JOHNSON, B.; LUNDVALL, B-A Promoting innovation systems as a response to the globalising learning economy. Nota Técnica 4 do Projeto: Arranjos e Sistemas Produtivos Locais e as Novas Politicas de Desenvolvimento Industrial e Tecnológico. Rio de Janeiro: Instituto de Economia, UFRJ. 2000.

LUNDVALL, B-A. Explaining interfirm cooperation and innovation: limits of the transaction cost approach. In: GRABHER, G. The embedded firm: on the socioeconomics of industrial networks. New York: [s.n.], 1993.

PENROSE, E. (1959) The Theory of the Growth of the Firm. 3. ed. New York: Oxford University Press, 1995.

PERRY, M. K. Vertical integration; determinants and effects. In: SCHMALENSEE, R.; WILLIG, R. D. Handbook of Industrial Organization. [S.1.]: Elsevier Science Publishers, v. 1,1989

PONDE, J. L. S. P. S. Coordenação e aprendizado: elementos para uma teoria das inovações nas firmas e nos mercados. Campinas, 1993. Dissertação (Mestrado) - Instituto de Economia, Universidade Estadual de Campinas.

WILLIAMSON, O. E. Markets and hierarchies: analysis and antitrust implications: a study in the economies of internal organization. New York: The Free Press, 1975.

. The economic institutions of capitalism. New York: The Free Press, 1985.

Comparative economic organization: the analysis of discrete structural alternatives. Administrative Science Review, n. 36, Jun. 1991. 